\title{
Krill Oil Prevents Atherosclerosis in an Experimental Model
}

\author{
(D) Yıldırım Gültekin, (1) Ali Bolat, (1) Atike Tekeli Kunt
}

Kırıkkale University School of Medicine, Department of Cardiovascular Surgery, Kırıkkale, Turkey

\begin{abstract}
Objectives: The major aim of coronary artery disease management is to reduce the formation and progression of atherosclerotic plaque. Omega-3 fatty acid supplementation that is obtained from fish has been shown to reduce cardiovascular events. Krill (Euphasia superba) are small crustaceans that live in cold seas like the Antarctic Ocean. Recently, due to its high content, and form of the eicosapentaenoic acid (EPA) and docosahexaenoic acid (DHA), krill oil has become popular in researches dealing with the prevention of cardiac disorders and cancer. This study aims to analyze the effect of krill oil supplements on atherosclerosis in rats treated with high-fat diet and streptozotocin-induced diabetes mellitus.
\end{abstract}

Materials and Methods: Twenty Sprague-Dawley male rats were split into two groups: the control group (C group) and the krill oil group (KO group). Each group was fed with a high-fat diet for six months and streptozotocin was injected subcutaneously to obtain an experimental model of atherosclerosis. The KO group received a $50 \mathrm{mg}$ daily supplement of krill oil orally. Rats were sacrificed after six months for biochemical and histopathological examinations of the aorta and coronary arteries.

Results: The atherosclerosis model was confirmed by elevated levels of low-density lipoprotein (LDL), triglyceride (TG), total cholesterol (TC), and glucose, also decreased insulin and high-density lipoprotein (HDL). The atherosclerosis index (TC/HDL) was lower in the $\mathrm{C}$ group compared to the $\mathrm{KO}$ group $(\mathrm{p}=0.012)$. Serum native thiol and total thiol levels were higher; however, the disulfide level was lower in the KO group. This result was statistically significant $(\mathrm{p}<0.001)$.

Address for Correspondence: Atike Tekeli Kunt, Kırıkkale University School of Medicine, Department of Cardiovascular Surgery, Kırıkkale, Turkey

e-mail: atikemd@gmail.com ORCID: orcid.org/0000-0001-9764-7393

Received: 05.05.2021 Accepted: 26.08.2021

Cite this article as: Yıldırım G, Bolat A, Tekeli Kunt A. Krill Oil Prevents Atherosclerosis in an Experimental Model.

EJCM 2021;9(3):150-157.

DOI: 10.32596/ejcm.galenos.2021-05-029

Presented in: This study was presented online on 01.10 .2020 at the $16^{\text {th }}$ International Congress of Innovations in Cardiology and Cardiovascular Surgery in Turkey.

${ }^{\circ}$ Copyright 2021 by Heart and Health Foundation of Turkey (TÜSAV) / E Journal of Cardiovascular Medicine published by Galenos Publishing House. 
In the $\mathrm{KO}$ group, there was a significant decrease in the number of foam cells discovered in the tissue examined from the aorta and coronary arteries with hematoxylin and eosin staining.

Conclusions: The present study indicates that krill oil supplements attenuate the number of foam cells in the aorta and coronary arteries, indicating the preventive effect of krill oil on atherosclerosis.

Keywords: Krill oil, omega-3, antioxidants, atherosclerosis, experimental model

\section{Introduction}

In 1904, Felix Marchand became the first person to use the word "atherosclerosis" to include the various arterial lesions and to emphasize the presence of lipid material in the lesions ${ }^{(1)}$. In addition to lipid accumulation in the vascular intima and wall, atherosclerosis is associated with inflammation ${ }^{(2,3)}$. These lesions cause luminal occlusion or may result in thrombosis and arterial embolism. Atherosclerosis manifests itself in the arterial vascular system as coronary artery disease (CAD), peripheral artery disease, carotid artery disease, renal artery occlusion, and abdominal aortic aneurysm. CAD is one of the leading causes of morbidity and mortality in the world. Therefore, the basic principle of combating $\mathrm{CAD}$ is to reduce atherosclerotic plaque formation and progression $^{(4)}$. The initial lesion of atherosclerosis is fatty streaking. This lesion occurs as a result of the accumulation of lipid-loaded macrophages in the intima of the arteries ${ }^{(5)}$. The main factors that lead to the formation of these fatty lines and atherosclerosis are impaired lipid metabolism, vascular cellular activation, and inflammation ${ }^{(6)}$. In addition to dyslipidemia, hyperglycemia, hypertension, and obesity are also modifiable risk factors of atherosclerosis and eventually CAD. A healthy and balanced diet with regular exercise is the most important recommendation to prevent atherosclerosis ${ }^{(7)}$. A healthy diet includes a low-fat diet, particularly low in saturated fats, to reduce serum cholesterol levels. Furthermore, in the case of dyslipidemia, serum cholesterol levels can be controlled with drugs such as statins ${ }^{(8)}$. Statins prevent the formation of atherosclerosis both by preventing the synthesis of cholesterol in the liver and by showing an anti-inflammatory effect on the artery wall ${ }^{(9)}$. In recent years, long-chain omega-3 polyunsaturated fatty acids such as EPA and DHA, which are mainly found in fish, have been gaining interest and starting to take their place in the prevention of atherosclerosis ${ }^{(10)}$. Krill (Euphausia superba) are small crustaceans that resemble shrimp in appearance and live in cold seas such as the Norwegian Sea and the Antarctic Ocean. Krill is more commonly known as whale food; however, it is also a food source for seals, squid, other fish, seabirds, and to a lesser extent humans. Krill oil is an important source of omega-3 and is obtained from krill. It is purer than fish oil, and it can be used wherever fish oil is used. Recently, due to its high omega- 3 content in the form of EPA and DHA, krill oil has become popular in research dealing with the prevention of cardiac disorders and cancer. Omega-3 found in normal fish oil differs from fatty acids, and its bioavailability is much higher. Apart from the fatty acids, krill oil contains triglycerides, vitamin A, vitamin E, tocopherol, astaxanthin, and flavonoid ${ }^{(11)}$.

There are many risk factors for atherosclerosis. One of these is hyperlipidemia and diabetes mellitus. This study aims to analyze the effect of the long-term administration of krill oil supplements on atherosclerosis in rats treated with high-fat diet and streptozotocin-induced diabetes mellitus.

\section{Materials and Methods}

The study protocol was approved by the Kurıkkale University Animal Experiments Local Ethics Committee (no: 18/05, date: 31.01 .2018 ). All animals used in the study 
were treated following the criteria specified in the Guide for the Care and Use of Laboratory Animals. Providing experimental animals and all experimental stages were carried out at Kırıkkale University Hüseyin Aytemiz Experimental Research and Application Laboratory.

\section{The Animals and Experiment Preparation}

This experimental study included a total of 20 male Sprague-Dawley rats weighing $255 \pm 25 \mathrm{~g}$ and aged three to four months. The animals were kept at a temperature of $21 \pm 1{ }^{\circ} \mathrm{C}$ and humidity of $50-55 \%$. A maximum of seven or eight rats were placed per cage. Water and food were provided ad libitum and all rats were fasted before the experiment and kept in a 12-hour light and 12-hour dark cycle.

The rats were randomized using a table of random numbers and divided into $\mathrm{C}$ and $\mathrm{KO}$ Groups, each containing 10 animals ${ }^{(12)}$. The body weights of the rats were measured and recorded at the beginning and end of the experiment. Since rats are atherogenesis-resistant animals, the atherogenesis model was applied ${ }^{(13)}$. Each group was fed with a high-fat diet and injected with a single dose of streptozotocin subcutaneously to obtain an experimental model of atherosclerosis ${ }^{(14,15)}$. The fat diet contained 31.5\% animal fat. Streptozotocin 40-80 mg/ kg (Glentham Life Sciences, England) was administered subcutaneously to both groups to produce diabetes mellitus. Three days after the injection of streptozotocin, the blood glucose from the tail vein of the rats was measured with a glucose meter (Accu-Chek ${ }^{\circledR}$ Active, Roche Diagnostics, Basel, Switzerland) working with the "glucose-oxidase peroxidase" method and the formation of diabetes mellitus was controlled. While a normal blood glucose level was accepted as $90-110 \mathrm{mg} / \mathrm{dL}$, those with blood glucose levels above $200 \mathrm{mg} / \mathrm{dL}$ were considered diabetic $^{(16)}$. Blood glucose levels were found to be above $200 \mathrm{mg} / \mathrm{dL}$ in all animals. Each day $50 \mathrm{mg}$ of krill oil was added to the KO Group in their daily diet by the gavage method (Superba ${ }^{\mathrm{TM}}$ Krill Oil, Aker BioMarine ASA, Oslo, Norway). All animals were fed with this diet for six months. The rats who died during the experiment were planned to be excluded from the study. Two animals from each group died before the experiment; therefore, both groups consisted of eight animals each.

\section{Anesthesia}

After six months, anesthesia was applied with $50 \mathrm{mg} /$ kg ketamine hydrochloride (Ketalar ${ }^{\circledR}$, Eczacıbaşı, Turkey) and $10 \mathrm{mg} / \mathrm{kg}$ xylazine hydrochloride (Alfazyme ${ }^{\circledR}$, Alfasan International BV, Woerden, Holland) intraperitoneally.

\section{Surgical Procedure}

All of the rats were placed in the supine position. The sternum was opened using surgical scissors to reach the heart. Animals were sacrificed after blood and tissue samples were taken.

\section{Biochemical Analysis of Blood}

Blood samples were taken from the right atrium for biochemical tests (Figure 1). Serum samples were centrifuged at 2,000 rpm for eight minutes and then kept at $-80^{\circ} \mathrm{C}$. An automatic biochemical analyzer, BS800M (Mindray, P.R. China), was used to measure the levels of HDL, LDL, TG, TC, glucose, and insulin. Then, the atherosclerosis index (TC/HDL) was calculated using these results ${ }^{(17)}$. Using the serum, native thiol $(\mathrm{mmol} / \mathrm{L})$, total thiol $(\mathrm{mmol} / \mathrm{L})$, and disulfide levels $(\mathrm{mmol} / \mathrm{L})$ were calculated spectrophotometrically (Shimadzu UV-1201 spectrophotometer, Kyoto, Japan).

\section{Histopathological Analysis}

Tissue samples were taken from the coronary arteries and ascending aorta for histopathological examination. Rats were sacrificed after biochemical and histopathological examinations. Ascending aorta and coronary artery tissues were kept in a $10 \%$ formol solution and sections parallel to the long axis were taken semi-perpendicularly for a routine tissue follow-up. After the tissue follow-up, samples were placed in paraffin, and sections 5-micron thick were taken from the paraffin blocks. Hematoxylineosin staining was used to detect foam cells in the walls of the aorta and coronary arteries (Bio-Optica, Milan, 
Italy). All images were digitized using a light microscope (Olympus AX80; Olympus Optical, Tokyo, Japan).

\section{Statistical Analysis}

The data obtained in the study were evaluated (SPSS Inc., U.S.A.) using Windows 16.0 program for statistical analysis. Descriptive statistics were given as mean \pm standard deviation (mean $\pm \mathrm{SD}$ ). Comparison of continuous and ordinal variables among the groups was performed with the Kruskal-Wallis variance analysis. The Mann-Whitney U test was used for group comparisons. For preventing significant inflation, a p-value $<0.05$ was considered statistically significant.

\section{Results}

Induction of atherosclerosis and diabetes in rats after a high-fat diet and streptozotocin injection was confirmed by elevated levels of TC, TG, and LDL and increased glucose and decreased insulin levels. The HDL and insulin levels in the $\mathrm{C}$ group were lower than in the $\mathrm{KO}$ group. $\mathrm{TC}$, LDL, TG, and glucose levels were found to be lower in the $\mathrm{KO}$ group than in the $\mathrm{C}$ group. A statistically significant difference was found in the $\mathrm{C}$ group atherosclerosis index (TC/HDL) when compared to the KO group. The results obtained are shown in Table 1.

Serum native thiol and total thiol levels measured in the $\mathrm{KO}$ group were lower than in the $\mathrm{C}$ group and the serum disulfide level in the $\mathrm{KO}$ group was lower than the $\mathrm{C}$ group. When the two groups were compared, a statistically significant difference was found $(p<0.001)$. The data are shown in Table 2.

There was no statistically significant difference in the pre-experiment body weights between the $\mathrm{KO}$ group and the $\mathrm{C}$ group. It was determined that the weight gain was less in the $\mathrm{K}$ group after the experiment. A statistically significant difference was found between the body weights after the experiment between the $\mathrm{KO}$ group and the $\mathrm{C}$ group. The results are shown in Table 3.

Table 1. Biochemical data in blood

\begin{tabular}{|c|c|c|c|}
\hline Parameter & $\begin{array}{l}\text { KO group } \\
(n=8) \\
\text { Mean } \pm S D\end{array}$ & $\begin{array}{l}\text { C group } \\
(n=8) \\
\text { Mean } \pm S D\end{array}$ & p-value \\
\hline HDL (mg/dL) & $22.51 \pm 2.64$ & $14.60 \pm 3.12$ & $<0.001$ \\
\hline LDL (mg/dL) & $29.33 \pm 1.41$ & $41.38 \pm 1.48$ & $<0.001$ \\
\hline TG (mg/dL) & $180.40 \pm 13.42$ & $219.01 \pm 42.16$ & 0.027 \\
\hline Atherosclerosis index (TC/HDL) & $2.74 \pm 1.65$ & $5.41 \pm 0.43$ & 0.012 \\
\hline Glucose (mg/dL) & $221.30 \pm 10.70$ & $259.55 \pm 14.25$ & $<0.001$ \\
\hline Insulin $(\mu \mathrm{U} / \mathrm{mL})$ & $24.12 \pm 0.35$ & $27.32 \pm 0.38$ & $<0.001$ \\
\hline
\end{tabular}

Table 2. The antioxidant markers of the groups in the study

\begin{tabular}{|l|l|l|l|}
\hline Parameter & $\begin{array}{l}\text { KO group } \\
(\mathbf{n = 8}) \\
\text { Mean } \pm \text { SD }\end{array}$ & $\begin{array}{l}\text { C group } \\
\text { (n=8) } \\
\text { Mean } \pm \text { SD }\end{array}$ & p-value \\
\hline Serum disulfide level (mmol/L) & $15.96 \pm 4.15$ & $20.17 \pm 0.65$ & $\mathbf{0 . 0 0 1}$ \\
\hline Serum native thiol level (mmol/L & $172.61 \pm 22.11$ & $78.31 \pm 11.95$ & $\mathbf{0 . 0 0 1}$ \\
\hline Serum total thiol level (mmol/L) & $267.15 \pm 16.42$ & $110.46 \pm 6.32$ & $\mathbf{0 . 0 0 1}$ \\
\hline KO: Krill oil, C: Control, SD: Standard deviation & & & \\
\hline
\end{tabular}


Table 3. Bodyweight before and after the experiment

\begin{tabular}{|c|c|c|c|}
\hline Parameter & $\begin{array}{l}\text { KO group } \\
(n=8) \\
\text { Mean } \pm \text { SD }\end{array}$ & $\begin{array}{l}\text { C group } \\
(n=8) \\
\text { Mean } \pm \text { SD }\end{array}$ & p-value \\
\hline Pre-experiment bodyweight (g) & $257.5 \pm 14.6$ & $251.4 \pm 12.9$ & 0.061 \\
\hline
\end{tabular}

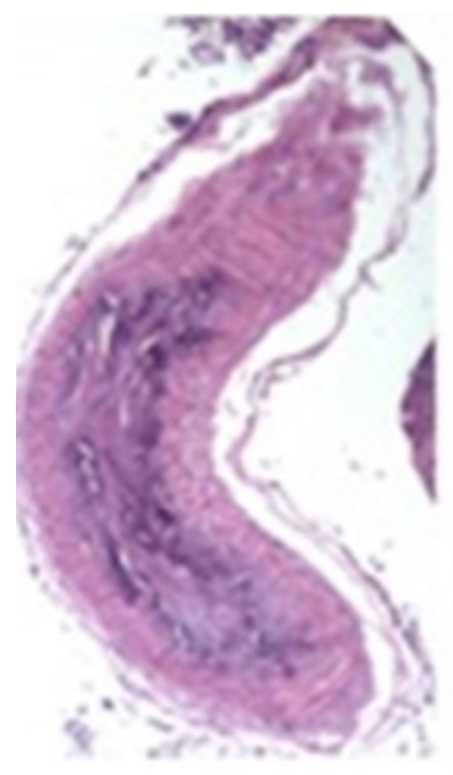

a

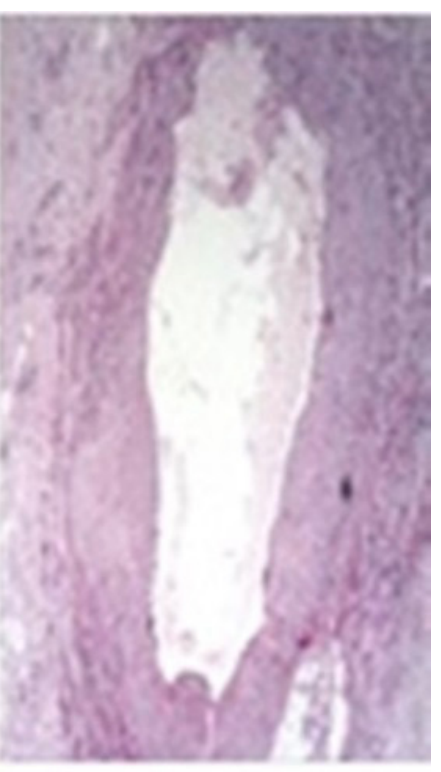

b

Figure 1. Hematoxylin and eosin staining of the aorta, and coronary artery tissue in the control group. a) shows medial calcific sclerosis, a thickened arterial wall and stenosis of the lumen. b) shows the irregular arterial lumen, inflammatory cells in the arterial wall and lumen

There was a significant increase in the number of foam cells in the aorta in the $\mathrm{C}$ group (Figure 1). Figure la shows medial calcific sclerosis, a thickened arterial wall, and stenosis of the lumen. These are the early signs of atherosclerosis.

Figure $1 \mathrm{~b}$ shows the irregular arterial lumen, inflammatory cells in the arterial wall and lumen, and migration of smooth muscle cells from media to intima.

The KO group showed a decreased number of foam cells, with a regular structure of the arterial wall and the intima. Images are shown in Figure 2.

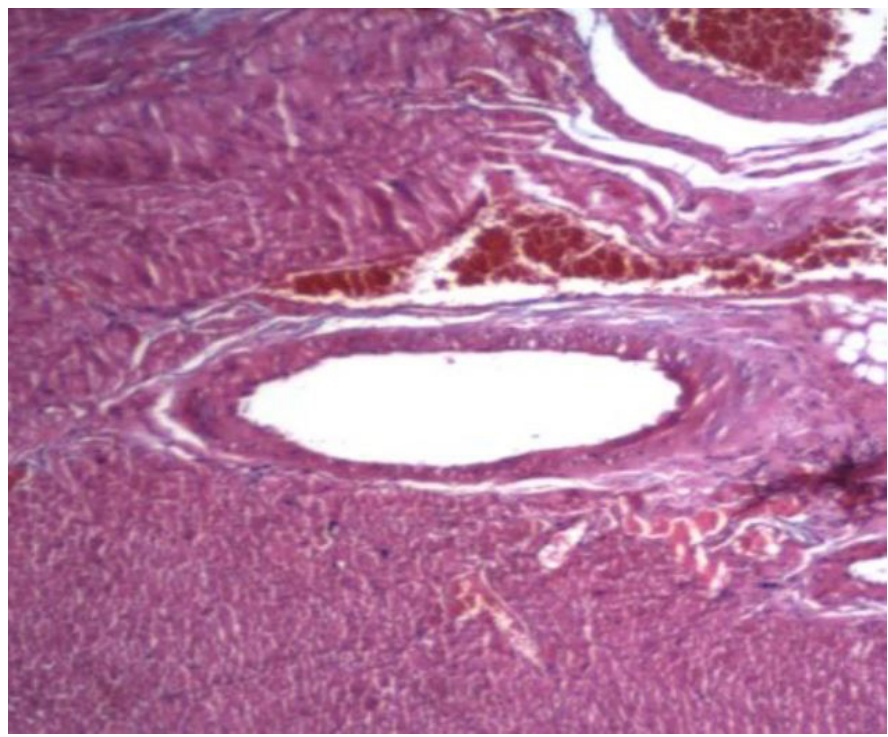

Figure 2. Hematoxylin and eosin staining in the aorta and coronary artery tissue in the krill oil group

\section{Discussion}

The main finding from this experimental study is that krill oil is proven to be effective in reducing the development of atherosclerosis in rats treated with highfat diet and streptozotocin-induced diabetes mellitus. This result was observed in the aorta and coronary arteries.

Atherosclerosis is the most significant cause of heart attacks and strokes, characterized by the thickening and hardening of the arterial walls. It begins in childhood and clinical consequences are visible after a long asymptomatic $\operatorname{period}^{(18)}$. Atherosclerotic lesions are formed during the chronic inflammatory process. In various studies on humans, causes such as dyslipidemia, diabetes mellitus, hypertension, smoking, older age, male gender, heredity, obesity, and lifestyle are among the modifiable and 
unchangeable risk factors for atherosclerosis. Lifestyle includes diet and physical activity, which has been shown to play a significant role in the prevention of cardiovascular disease ${ }^{(19)}$. Believed to protect the cardiovascular system, nutrients such as fish oil and krill oil, which are sources of omega-3, have become very popular and are widely available on the market; reports on their health benefits are driving a steady increase in seafood consumption. Even though human consumption of fish-based food products has increased, the amount of fishing has not risen for a long time and is not expected to grow. A constant increase in fish consumption alongside a decrease in fish resources has created an imbalance between supply and demand. This situation has led to the need for new supplies. Krill, a crustacean living in the Antarctic Ocean, has come to the forefront as such a resource ${ }^{(20)}$.

In epidemiological studies, it has been reported that the risk of CAD increases as the TC and LDL levels increase in humans. It has been stated that the oxidative change of LDL has a significant effect on the pathogen of atherosclerosis ${ }^{(21,22)}$. Many human and animal studies have shown that fish and krill oils cause significant changes in serum lipid levels ${ }^{(23)}$. When studies investigating the effect of $\mathrm{KO}$ on serum lipids in humans were examined, a meta-analysis was found to report a decrease in LDL and $\mathrm{TG}^{(24,25)}$.

Metabolic syndrome is an endocrinopathy in which insulin resistance starts with systemic disorders such as dyslipidemia, hypertension, obesity, diabetes mellitus, and CAD. It does this by causing atherosclerosis in the $\operatorname{arteries}^{(26)}$. In our study, there was no difference in the mean body weight between the groups at the beginning of the experiment; however, a statistically significant difference was found at the end of the study ( $p=0.061)$. It was determined that the average weight gain was higher in the $\mathrm{C}$ group. The more severely impaired lipid profile and reduced glucose and insulin levels seen in the $\mathrm{C}$ group may explain the greater weight gain in this group. In addition, low insulin levels and increased glucose levels were detected in both groups with the experimental diabetes mellitus induced by streptozotocin. The high glucose level and low insulin level in the $\mathrm{C}$ group were higher than the KO group. This result was statistically significant $(p<0.001)$. These results may indicate that krill oil is effective in preventing the development of atherosclerosis.

The atherosclerosis index is used to evaluate cardiovascular risk and is calculated using the ratio of serum TC to HDL; this index is a strong indicator of coronary heart disease. The TG/HDL ratio evaluates the risk of CAD compared to TC or LDL cholesterol levels. In hypercholesterolemic animals, there is an increase in atherosclerosis index, which is a risk factor for atherosclerosis ${ }^{(27)}$. Our results showed a statistically significant difference between the C Group and KO Group regarding the atherosclerosis index $(\mathrm{p}=0.012)$. According to their calculated atherosclerotic index value, this result puts the $\mathrm{C}$ group in the high cardiovascular risk group.

Krill oil contains omega-3 fatty acids and a variety of antioxidants that differ from those in fish oil ${ }^{(28)}$. These antioxidant properties are derived from astaxanthin, vitamin A, vitamin E, marine tocopherol, and flavonoid ${ }^{(29,30)}$. Unlike fish oil, krill oil has a high content of antioxidants, which has been shown in many studies $^{(31,32)}$. Krill oil also does not have EPA and DHA in the form of TG as in fish oil, instead, omega-3 fatty acids bind to phospholipids ${ }^{(33)}$. This binding of omega-3 fatty acids, mainly in the form of phosphatidylcholine, is thought to increase both its bioavailability and antioxidant properties ${ }^{(34)}$. In many studies, it has been reported that chronic inflammation plays a main role in the pathophysiology of atherosclerosis ${ }^{(35)}$. Antioxidants have been shown in studies to reduce inflammation ${ }^{(36)}$. Native thiol, total thiol, and disulfide levels examined from serum in our study are antioxidants, which are indicators of oxidative stress ${ }^{(37)}$. They have critical roles in thiol-disulfide homeostasis, antioxidant protection, detoxification, apoptosis, regulation of enzymatic activity, and cellular signaling mechanisms ${ }^{(38)}$. In our study, native thiol and total thiol levels were found to be higher and 
disulfide levels to be lower in the $\mathrm{KO}$ group compared to the $C$ group $(p<0.001)$. From these results, due to the antioxidant content of krill oil, we can say that it may be more effective in preventing the development of atherosclerosis.

The first stage of atherosclerosis that can be seen under a microscope is the formation of fatty streaks from foam cells ${ }^{(39)}$. Parolini et $\mathrm{al}^{(40)}$. created an atherosclerosis experimental model on mice with apoE-deficiency. Throughout their studies in which they wanted to show the effect of krill oil on lipid levels and histopathological examination, they demonstrated that as a result of histopathological examination of the ascending aorta, abdominal aorta, and iliac arteries, the development of atherosclerotic plaque in krill oil decreased. In our study, as a result of histopathological examination of the ascending aorta and coronary artery tissues stained with hematoxylineosin, an important increase in the number of foam cells, fatty streak, medial calcific sclerosis, and a thickened arterial wall, which are the early signs of atherosclerosis in the aorta, was found in the control group. In addition to these findings, it showed the irregular arterial lumen, inflammatory cells in the artery wall and lumen, and the migration of smooth muscle cells from the environment to the intima. There was a decreased number of foam cells with a regular structure of the arterial wall and the intima in the KO Group. These histopathological results obtained in the KO Group show that krill oil has a protective effect from atherosclerosis. This result is similar to the results of Parolini et al. ${ }^{(40)}$ We also demonstrated the antioxidant effect of krill oil by its change in oxidative stress markers in the blood.

\section{Study Limitations}

The limitation of this study is that pro-inflammatory oxidant markers secreted by foam cells were not examined.

\section{Conclusion}

Krill oil, as a new source of EPA and DHA, is suggested to attenuate atherosclerosis in the present study. Prospective randomized trials using krill oil as a supplement for humans are warranted to confirm these results.

\section{Acknowledgments}

We would like to thank Yaşar Şimsek, who is in charge of Hüseyin Aytemiz Experimental Research and Application Laboratory, for his support and assistance in the study.

\section{Ethics}

Ethics Committee Approval: The study protocol was approved by the Kirikkale University Animal Experiments Local Ethics Committee (no: 18/05, date: 31.01.2018).

Informed Consent: Not obtained since the study is an animal experiment study.

Peer-review: Externally peer-reviewed.

\section{Authorship Contributions}

Surgical and Medical Practices: G.Y., A.B., A.T.K., Concept: G.Y., A.B., Design: G.Y., A.B., A.T.K.., Data Collection or Processing: G.Y., A.B., Analysis or Interpretation: G.Y., A.T.K., Literature Search: G.Y., A.T.G., Writing: G.Y., A.B., A.T.K.

Conflict of Interest: The authors declared no conflicts of interest concerning to the authorship and/or publication of this article.

Financial Disclosure: This study was supported by the Kırıkkale University Scientific Research Project (project number: 2019/175).

\section{References}

1. Schwartz CJ, Mitchell JR. The morphology, terminology and pathogenesis of arterial plaques. Postgrad Med J 1962;38:25-34.

2. Libby P. Inflammation in atherosclerosis. Arterioscler Thromb Vasc Biol 2012;32:2045-51

3. Wang T, Palucci D, Law K, Yanagawa B, Yam J, Butany J. Atherosclerosis: pathogenesis and pathology. Diag Histopathol 2012;18:461-7.

4. Mozaffarian D, Benjamin EJ, Go AS, et al. Heart Disease and Stroke Statistics-2016 Update: A Report From the American Heart Association. Circulation 2016;133:e38-360.

5. Stary HC, Chandler AB, Glagov S, et al. A definition of initial, fatty streak, and intermediate lesions of atherosclerosis. A report from the Committee 
on Vascular Lesions of the Council on Arteriosclerosis, American Heart Association. Arterioscler Thromb 1994;14:840-56.

6. Sitia S, Tomasoni L, Atzeni F, et al. From endothelial dysfunction to atherosclerosis. Autoimmun Rev 2010;9:830-4.

7. Mozaffarian D, Appel LJ, Van Horn L. Components of a cardioprotective diet: new insights. Circulation 2011;123:2870-91.

8. Aikawa M, Libby P. Lipid lowering therapy in atherosclerosis. Semin Vasc Med 2004;4:357-66.

9. Pinal-Fernandez I, Casal-Dominguez M, Mammen AL. Statins: pros and cons. Med Clin (Barc) 2018;150:398-402.

10. Le Goff W. A new piece in the puzzling effect of n-3 fatty acids on atherosclerosis? Atherosclerosis 2014;235:358-62.

11. Ulven SM, Holven KB. Comparison of bioavailability of krill oil versus fish oil and health effect. Vasc Health Risk Manag 2015;11:511-24.

12. Charan J, Kantharia ND. How to calculate sample size in animal studies? J Pharmacol Pharmacother 2013;4:303-6.

13. Emre B, Salgırlı Y. Deneklerin Fizyolojik Özellikleri ve Deneysel Çalışmalarda Model Oluşturmadaki Zorlukları. J Clin Anal Med 2010;2:2632.

14. Silva AP, Guimarães DE, Mizurini DM, et al. Dietary fatty acids early in life affect lipid metabolism and adiposity in young rats. Lipids 2006;41:535-41.

15. Kurçer Z, Karaoğlu D. The use of Alloxan and Streptozotocin in Experimental Diabetes Models. Turk Jem 2012;16:34-40.

16. Jaouhari JT, Lazrek HB, Jana M. The hypoglycemic activity of Zygophyllum gaetulum extracts in alloxan-induced hyperglycemic rats. J Ethnopharmacol 2000;69:17-20.

17. Chu NF, Lin FH, Chin HC, Hong YJ. Association between interleukin-6 receptor gene variations and atherosclerotic lipid profiles among young adolescents in Taiwan. Lipids Health Dis 2011;10:136.

18. McMahan CA, Gidding SS, Viikari JS, et al. Association of Pathobiologic Determinants of Atherosclerosis in Youth risk score and 15-year change in risk score with carotid artery intima-media thickness in young adults (from the Cardiovascular Risk in Young Finns Study). Am J Cardiol 2007; 100:1124-9.

19. Gülel O. Kardiyovasküler risk faktörleri. Journal of Experimental and Clinical Medicine 2012;29:107-16.

20. Blanco M, Sotelo CG, Chapela MJ, Perez-Martın RI. Towards sustainable and efficient use of fishery resources: present and future trends. Trends in Food Science \& Technology 2007;18:29-36.

21. Meyer AS, Heinonen M, Frankel EN. Antioxidant interactions of catechin, cyanidin, cafeic acid, quercetin, and ellagic acid on human LDL oxidation. Food Chem 1998;61:71-5.

22. Maron DJ, Ridker PM, Grundy SM, Pearson TA. Preventive strategies for coronary heart disease. In Hurst's the heart, Chapter 51, V. Fuster, R.A., Walsh, R.A., O’Rourke, P., Poole-Wilson, eds. McGraw-Hill; New York: 2008;51:1203-34

23. Chang CL, Torrejon C, Jung UJ, Graf K, Deckelbaum RJ. .Incremental replacement of saturated fats by $n-3$ fatty acids in high-fat, high-cholesterol diets reduces elevated plasma lipid levels and arterial lipoprotein lipase, macrophages and atherosclerosis in LDLR-/- mice. Atherosclerosis 2014;234:401-9

24. Ursoniu S, Sahebkar A, Serban MC, et al. Lipid-modifying effects of krill oil in humans: systematic review and meta-analysis of randomized controlled trials. Nutr Rev 2017;75:361-73.

25. Tandy S, Chung RW, Wat E, et al. Dietary krill oil supplementation reduces hepatic steatosis, glycemia, and hypercholesterolemia in high-fat-fed mice. J Agric Food Chem 2009;57:9339-45.

26. İslamoğlu Y, Koplay M, Sunay S, Açıkel M. Obezite ve metabolik sendrom. Tıp Araștırmaları Dergisi 2008;6:168-74.

27. Kinosian B, Glick H, Garland G. Cholesterol and coronary heart disease: predicting risks by levels and ratios. Ann Intern Med 1994;121:641-7.

28. Tillander V, Bjørndal B, Burri L, et al. Fish oil and krill oil supplementations differentially regulate lipid catabolic and synthetic pathways in mice. Nutr Metab (Lond) 2014;11:20.

29. Maki KC, Reeves MS, Farmer M, et al. Krill oil supplementation increases plasma concentrations of eicosapentaenoic and docosahexaenoic acids in overweight and obese men and women. Nutr Res 2009;29:609-15.

30. Hussein G, Nakagawa T, Goto H, et al. Astaxanthin ameliorates features of metabolic syndrome in SHR/NDmcr-cp. Life Sci 2007;80:522-9.

31. Ikeuchi M, Koyama T, Takahashi J, Yazawa K. Effects of astaxanthin in obese mice fed a high-fat diet. Biosci Biotechnol Biochem 2007;71:893-9.

32. Yeral I, Sayan CD, Karaca G, et al. What is the protective effect of krill oil on rat ovary against ischemia-reperfusion injury? J Obstet Gynaecol Res 2019;45:592-9.

33. Ahn SH, Lim SJ, Ryu YM, Park HR, Suh HJ, Han SH. Absorption rate of krill oil and fish oil in blood and brain of rats. Lipids Health Dis 2018; $17: 162$.

34. Ramprasath VR, Eyal I, Zchut S, Jones PJ. Enhanced increase of omega-3 index in healthy individuals with response to 4-week n-3 fatty acid supplementation from krill oil versus fish oil. Lipids Health Dis $2013 ; 12: 178$.

35. Wales KM, Kavazos K, Nataatmadja M, Brooks PR, Williams C, Russell FD. N-3 PUFAs protect against aortic inflammation and oxidative stress in angiotensin II-infused apolipoprotein E-/- mice. PLoS One 2014;9:e112816.

36. Aggarwal BB, Harikumar KB. Potential therapeutic effects of curcumin, the anti-inflammatory agent, against neurodegenerative, cardiovascular, pulmonary, metabolic, autoimmune and neoplastic diseases. Int J Biochem Cell Biol 2009;41:40-59.

37. Oliveira PVS, Laurindo FRM. Implications of plasma thiol redox in disease. Clin Sci (Lond) 2018;132:1257-80

38. Biswas S, Chida AS, Rahman I. Redox modifications of protein-thiols: emerging roles in cell signaling. Biochem Pharmacol 2006;71:551-64.

39. Harrison DG. Endothelial function and oxidant stress. Clin Cardiol 1997;20(11 Suppl 2):II-11-7.

40. Parolini C, Bjorndal B, Busnelli M, et al. Effect of Dietary Components from Antarctic Krill on Atherosclerosis in apoE-Deficient Mice. Mol Nutr Food Res 2017;61. 